\title{
Sensorless nonlinear sliding mode control of the induction machine at very low speed using FM-MRAS observer
}

\author{
Mokhtar Touam ${ }^{1}$, Mohammed Chenafa ${ }^{2}$, Soufyane Chekroun ${ }^{3}$, Ramzi Salim $^{4}$ \\ ${ }_{1,2,4}$ Department of Electrical Engineering, Laboratory of Automatics \& Systems Analysis (LAAS), Polytechnic National \\ School of Oran Maurice Audin, Algeria \\ ${ }^{3}$ Department of Electrical Engineering, University Mustapha Stambouli of Mascara, Mascara-Algeria
}

\begin{tabular}{l} 
Article Info \\
\hline Article history: \\
Received Apr 10, 2021 \\
Revised Sep 3, 2021 \\
Accepted Sep 10, 2021 \\
\hline
\end{tabular}

\section{Keywords:}

Fuzzy logic

Induction motor

Mutual MRAS

Sensorless

Sliding mode

\begin{abstract}
The induction motor is complex because its dynamic is nonlinear, multivariable and highly coupled. In addition, the induction motor (IM) controller design can be degraded due to wide ranges operating speed specially in low and near-zero speeds and also to variation of interval parameters such as the stator resistance change because of stator heating during operation. Our contribution is the use of a nonlinear sliding mode control using a fuzzy mutual reference adaptive system observer based on two fuzzy adaptation mechanisms to estimate both rotor speed and stator resistance. The proposed work was verified and compared by simulation and tested in various ranges of speed with motor and regenerating regions of operation. The results show that the proposed approach has proved good effectiveness in tracking and observation.
\end{abstract}

This is an open access article under the CC BY-SA license.

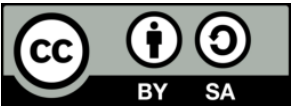

\section{Corresponding Author:}

Mokhtar Touam

Department of Electrical Engineering

Laboratory (LAAS), Polytechnic National School of Oran

BP.1523 El Mnaouer, 31000 Oran-Algeria

Email: mokhtartouam@gmail.com

\section{INTRODUCTION}

The industry is often interested in reducing the number of sensors among them the induction motor speed sensors. Since the publication of the survey by [1] then [2]-[4], significant interests on sensorless sliding mode control of induction motor have been developed in the control research due to the possibility to implement this control in industrial applications using new power electronics technology and availability cheap and fast computation. Despite the important developments of the sensorless control laws above but they suffer from large computation time, complexity, parameters variation, and limited bandwidth control in the low and near-zero speed regions estimation.

In this paper, a nonlinear sliding mode speed and rotor flux control combined with a stable fuzzy mutual model reference adaptive system (FM-MRAS) speed and stator resistance estimation for the induction motor drive has been developed. By combination the ideas of [5]-[8], the proposed FM-MRAS utilizes two models called as reference and adjustable models whose based on the rotor flux errors vectors [9]-[12]. Then, these errors are used drive adaptation mechanisms based on the fuzzy logic that generates in parallel the estimated speed and stator resistance, this parallel estimation is designed based on the concept of hyperstability [6] in order to make the system asymptotically stable. The important advantage of using fuzzy logic is robustness against parameter variations. The whole proposed system robustness, stability, effectiveness in tracking is tested in simulation. Finally, some comments are presented. 


\section{MATHEMATICAL MODEL OF INDUCTION MOTOR}

The model used is the model whose electrical quantities are all expressed in a fixed frame linked to the stator and which will be qualified $\operatorname{model}(\alpha, \beta)$. The model is given by [13], [14].

$$
\left\{\begin{array}{c}
\dot{x}=f(x)+g \cdot u \\
y=\square(x)
\end{array}\right.
$$

With

$$
\begin{cases}u & =\left[\begin{array}{llll}
u_{s \alpha} & u_{s \beta}
\end{array}\right]^{T} \\
x & =\left[\begin{array}{llllll}
i_{s \alpha} & i_{s \beta} & \psi_{r \alpha} & \psi_{r \beta} & \Omega_{r}
\end{array}\right]^{T}=\left[\begin{array}{lllll}
x_{1} & x_{2} & x_{3} & x_{4} & x_{5}
\end{array}\right]^{T}\end{cases}
$$

The state vector $\boldsymbol{x}$ is composed of two electrical states $\left(i_{s \alpha}, i_{s \beta}\right)$ and two magnetic states $\left(\psi_{r \alpha}, \psi_{r \beta}\right)$ and a state representing the rotational speed of the rotor $\Omega_{r}$, this speed will be presented by a mechanical equation $f, g$ and $\square$ are functions of the variables $x$.Hence the nonlinear system is of order 5 .

$$
\left\{\begin{array}{c}
\dot{x}_{1}=-\lambda x_{1}+\frac{\Gamma}{T_{r}} x_{3}+p \Gamma x_{4} x_{5}+\delta u_{s \alpha} \\
\dot{x}_{2}=-\lambda x_{2}+\frac{\Gamma}{T_{r}} x_{4}-p \Gamma x_{3} x_{5}+\delta u_{s \beta} \\
\dot{x}_{3}=\frac{L_{m}}{T_{r}} x_{1}-\frac{1}{T_{r}} x_{3}-p x_{4} x_{5} \\
\dot{x}_{4}=\frac{L_{m}}{T_{r}} x_{2}-\frac{1}{T_{r}} x_{4}+p x_{3} x_{5} \\
\dot{x}_{5}=\eta\left(x_{2} x_{3}-x_{1} x_{4}\right)-\frac{1}{J} C_{r}
\end{array}\right.
$$

with

$$
\lambda=\frac{R_{s}}{\sigma L_{s}}+\frac{1}{T_{r}}\left(\frac{1-\sigma}{\sigma}\right) ; \delta=\frac{1}{\sigma L_{s}} ; \quad \eta=\frac{p L_{m}}{J L_{r}} ; \quad \Gamma=\frac{1}{L_{m}}\left(\frac{1-\sigma}{\sigma}\right) ; T_{r}=\frac{L_{r}}{R_{r}} ; \sigma=1-\frac{L_{m}^{2}}{L_{s} L_{r}}
$$

Where $R_{S}$ is the stator resistance; $R_{r}$ is the rotor resistance; $L_{S}$ is the stator inductance; $L_{r}$ is the rotor inductance; $L_{m}$ is the mutual inductance; $T_{r}$ rotor time constant; $\sigma$ is the leakage coefficient; $p$ is the number of pole pairs; $J$ is moment of inertia; $C_{r}$ is the load torque.

\section{NONLINEAR SLIDING MODE CONTROL}

\subsection{Search for a control ensuring a sliding mode}

Definition 4. The control of Figure 1 presents a problem of chattering effects due to switching delays. To remedy this problem, we must choose a switching curve called sliding surface $S(t)$. The goal we are looking for is to join from the initial state the curve, then force the trajectory to stay on this surface.

$$
S(t)=\left(\frac{d}{d t}+k\right)^{n-1} e
$$

where e is the tracking error that it is equal to the difference between system state space reference and the system state space $\left(e=x_{r e f}-x\right)$, $\mathrm{k}$ is the weighting factor that must be strictly positive and $n$ is the degree of sliding mode surface [2]. Then, the dynamics of the system will be fixed by the equation of the sliding surface, and the origin will be joined with the time constant $k$.

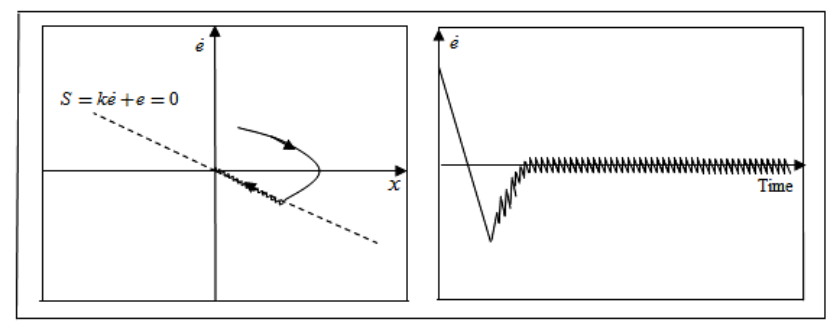

Figure1. Chattering effects and switching system on the sliding surface 
Theorem 4. (Globalstability) assume that there exists a scalar function V (Lyapunov function) of the state $\mathrm{x}$, with continuous first order derivatives such that.

- $\quad V(x)=\frac{1}{2} S^{2}$ is positive definite.

- $\quad \dot{V}(x)=S \dot{S}$ is negative definite.

- $\quad V(x) \rightarrow \infty$ as $\|x\| \rightarrow \infty$

then the equilibrium at the origin $S=0$ is globally asymptotically stable [2]. In other words, to follow the desired state, it's enough to make the sliding surface attractive $(S \dot{S}<0)$ and invariant $(\dot{S}=0)$ [15]. To eliminate the uncertain effect of the model and external disturbance, the sliding mode control law is defined by adding a command commuting $U_{c}$ to the equivalent command $U_{e q}$ in the form [16]-[18].

$$
U=U_{e q}+U_{c}
$$

with

$$
U_{c}=c \operatorname{sign}(S)
$$

$c$ is a constant and is chosen enough positive to satisfy attractivity and stability conditions.

\subsection{Selection of the control law}

Our goal is to generate a control law $\left[\begin{array}{ll}u_{s \alpha} & u_{s \beta}\end{array}\right]^{T}$ using the sliding control theory. The states considered for the induction motor control are: Speed and rotor flux $\left(\Omega_{r}, \Psi_{r}\right)$. In the control of the machine, it is necessary to ensure the control of the flux then of the speed, when the dynamics of speed is the slowest. For convenience of calculation, we will take [19], [20].

$$
\Psi_{r}=\psi_{r}^{2}=\psi_{r \alpha}^{2}+\psi_{r \beta}^{2}=x_{3}^{2}+x_{4}^{2}
$$

Its corresponding derivative gives.

$$
\dot{\Psi}_{r}=2 x_{3} \dot{x}_{3}+2 x_{4} \dot{x}_{4}
$$

According to the (4) the choice of the sliding surfaces of the variables to controlare given in the form of a first-order surface system.

$$
\left\{\begin{array}{l}
S_{1}=k_{1}\left(x_{5}-\Omega_{r_{r e f}}\right)+\left(\dot{x}_{5}-\dot{\Omega}_{r_{r e f}}\right) \\
S_{2}=k_{2}\left(\Psi_{r}-\Psi_{r_{r e f}}\right)+\left(\dot{\Psi}_{r}-\dot{\Psi}_{r_{r e f}}\right)
\end{array}\right.
$$

The successive derivatives of $S_{1}$ and $S_{2}$ will be

$$
\left\{\begin{array}{l}
\dot{S}_{1}=k_{1}\left(\dot{x}_{5}-\dot{\Omega}_{r_{r e f}}\right)+\left(\ddot{x}_{5}-\ddot{\Omega}_{r_{r e f}}\right) \\
\dot{S}_{2}=k_{2}\left(\dot{\Psi}_{r}-\dot{\Psi}_{r_{r e f}}\right)+\left(\ddot{\Psi}_{r}-\ddot{\Psi}_{r_{r e f}}\right)
\end{array}\right.
$$

Using the system (3) and (10), the development of calculus gives us.

$$
\left\{\begin{array}{l}
\dot{S}_{1}=\left(k_{1}-\frac{1}{T_{r}}-\lambda\right) \eta \xi_{2}-k_{1} \frac{1}{J} C_{r}-p x_{5} \eta\left(\xi_{1}+\Gamma \Psi_{r}\right)-k_{1} \dot{\Omega}_{r_{r e f}}-\ddot{\Omega}_{r_{r e f}} \\
+\delta \eta\left(x_{3} u_{s \beta}-x_{4} u_{s \alpha}\right) \\
\quad \dot{S}_{2}=\frac{2}{T_{r}}\left(\frac{2+L_{m} \Gamma}{T_{r}}-k_{2}\right) \Psi_{r}+\frac{2 L_{m}}{T_{r}}\left(\frac{L_{m}}{T_{r}} \xi_{3}+\left(k_{2}-\frac{3}{T_{r}}-\lambda\right) \xi_{1}+p x_{5} \xi_{2}\right) \\
\quad-k_{2} \dot{\Psi}_{r_{r e f}}-\ddot{\Psi}_{r_{r e f}}+\frac{2 \delta}{T_{r}} L_{m}\left(x_{4} u_{s \beta}+x_{3} u_{s \alpha}\right)
\end{array}\right.
$$

Such as.

$$
\begin{aligned}
& x_{1}=x_{1} x_{3}+x_{2} x_{4} \\
& x_{2}=x_{2} x_{3}+x_{1} x_{4} \\
& x_{3}=x_{1}^{2}+x_{2}^{2}
\end{aligned}
$$


The system (11) can be rearranged into the following matrix form.

$$
\underset{\dot{S}}{\left[\begin{array}{c}
S_{1} \\
\dot{S}_{2}
\end{array}\right]}=\underbrace{\left[\begin{array}{c}
F_{1} \\
F_{2}
\end{array}\right]+\underbrace{\left[\begin{array}{cc}
-\delta x_{4} & \delta x_{3} \\
\delta L_{m} x_{3} & \delta L_{m} x_{4}
\end{array}\right]}_{D}}_{F}\left[\begin{array}{l}
u_{s \alpha} \\
u_{s \beta}
\end{array}\right]
$$

with

$$
\left\{\begin{array}{l}
F_{1}=\left(k_{1}-\frac{1}{T_{r}}-\lambda\right) \xi_{2}-k_{1} \frac{1}{J \eta} C_{r}-p x_{5}\left(\xi_{1}+\Gamma \Psi_{r}\right)-k_{1} \frac{1}{\eta} \dot{\Omega}_{r e f}-\frac{1}{\eta} \ddot{\Omega}_{r e f} \\
F_{2}=\left(\frac{2+L_{m} K}{T_{r}}-k_{2}\right) \Psi_{r}+L_{m}\left(\frac{L_{m}}{T_{r}} \xi_{3}+\left(k_{2}-\frac{3}{T_{r}}-\lambda\right) \xi_{1}+p x_{5} \xi_{2}\right)
\end{array}\right.
$$

To check the Lyaponov's stability condition, one must have.

$$
\dot{S}=-c \operatorname{sign}(S)
$$

Equalizing (12) and (14) we will have.

$$
U=-D^{-1} c \operatorname{sign}(S)-D^{-1} F
$$

According to (5) the control law components are given by.

$$
\left\{\begin{array}{c}
U_{e q}=-D^{-1} F \\
U_{c}=-D^{-1} c \operatorname{sign}(S)
\end{array}\right.
$$

\section{FUZZYMUTUALMRASOBSERVER}

\subsection{MRAS based rotor speed estimation}

The principle of speed estimation by MRAS based on rotor flux consists in comparing the outputs of two flux estimators obtained by different formulations. The first estimator is based on the stator equations defining a model in voltage called the reference model. This model is used to estimate the components flux $\psi_{r \alpha_{V}}$ and $\psi_{r \beta_{V}}$ from the measurement of voltages and stator currents; being independent of the speed to estimate it according to the following [5], [7], [21].

$$
\frac{d \psi_{r_{V}}}{d t}=\frac{d}{d t}\left[\begin{array}{l}
\psi_{r \alpha_{V}} \\
\psi_{r \beta_{V}}
\end{array}\right]=\frac{L_{r}}{L_{m}}\left\{\left[\begin{array}{l}
u_{s \alpha} \\
u_{s \beta}
\end{array}\right]-R_{s}\left[\begin{array}{l}
i_{s \alpha} \\
i_{s \beta}
\end{array}\right]-\sigma L_{s} \frac{d}{d t}\left[\begin{array}{l}
i_{s \alpha} \\
i_{s \beta}
\end{array}\right]\right\}
$$

The second, called adjustable or adaptive model, is described by the rotor equations to estimatethe components flux $\psi_{r \alpha_{I}}$ and $\psi_{r \beta_{I}}$; Being explicitly linked to speed, he defines a current model is being as.

$$
\frac{d \widehat{\psi}_{r_{I}}}{d t}=\frac{d}{d t}\left[\begin{array}{l}
\hat{\psi}_{r \alpha_{I}} \\
\hat{\psi}_{r \beta_{I}}
\end{array}\right]=\left\{-\frac{1}{T_{r}}\left[\begin{array}{ll}
1 & 0 \\
0 & 1
\end{array}\right]-\widehat{\omega}_{r}\left[\begin{array}{cc}
0 & -1 \\
1 & 0
\end{array}\right]\right\}\left[\begin{array}{l}
\hat{\psi}_{r \alpha} \\
\hat{\psi}_{r \beta}
\end{array}\right]+\frac{L_{m}}{T_{r}}\left[\begin{array}{l}
i_{s \alpha} \\
i_{s \beta}
\end{array}\right]
$$

Such as $\widehat{\omega}_{r}$ is the rotor pulsation with: $\widehat{\omega}_{r}=p \cdot \widehat{\Omega}_{r}$.

The difference $e_{\omega_{r}}$ between the components of the rotor flux delivered at the outputs of the two models is used to drive an adaptation mechanism whose objective is to generate the value of the estimated speed whitch then reapplied to the input of the adjustable model with.

$$
e_{\omega_{r}}=\left(\psi_{r \beta_{V}} \widehat{\psi}_{r \alpha_{I}}-\psi_{r \alpha_{V}} \widehat{\psi}_{r \beta_{I}}\right)
$$

and

$$
\widehat{\omega}_{r}=\left(k_{p_{\omega_{r}}}+\frac{k_{i_{\omega_{r}}}}{s}\right) e_{\omega_{r}}
$$

Figure 2, shows the structure of a classical MRAS speed estimator based on adaptation low generated by the adaptation mechanism, which consists of a simple PI-type regulator performing a proportional-integral 
correction for the induction motor. Although easy to implement this approach, its stability and fast convergence, it has some major disadvantages as its dynamic performance sensitivity to parametric variations and the accuracy of the estimate is degraded at low and near-zero speeds. The stator resistance variation under operating conditions deteriorates the accuracy of the estimate, by modifying at low speed the amplitude and the phase of the rotor flux delivered by the reference model. To eliminate those disadvantages, it's necessary to introduce a new method of estimation. This method based on simultaneous and parallel estimation of the rotor speed and the stator resistance of the induction motor known as the mutual-MRAS approach.

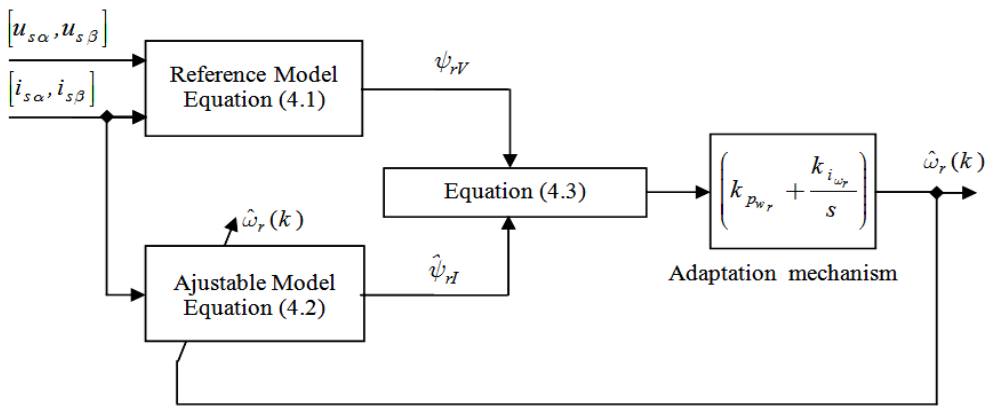

Figure 2. Structure of classical MRAS speed estimator based on rotor flux

In this approach, we introduce a second adaptation mechanism to estimate $R_{s}$ using the same PI-type regulator in parallel with the $\omega_{r}$ adaptaion mechanism, then the error of stator resistance proposed by Popov's hyperstability theoryis represented is being as.

$$
e_{R s}=i_{s \alpha} \cdot\left(\hat{\psi}_{r \alpha_{V}}-\hat{\psi}_{r \alpha_{I}}\right)+i_{s \beta} \cdot\left(\hat{\psi}_{r \beta_{V}}-\hat{\psi}_{r \beta_{I}}\right)
$$

and

$$
\hat{R}_{s}=\left(k_{p_{R_{S}}}+\frac{k_{i_{R_{S}}}}{s}\right) e_{R_{S}}
$$

\subsection{Proposed observer approach}

In order to improve the performance of the estimation in terms of convergence and robustness, but also to avoid the difficulties of setting the PI regulators, we proposed the idea to preserve the basic structure of the mutual-MRAS estimator and to use two fuzzy-PI nonlinear controllers forming the adaptation mechanisms. This new estimator is of a hybrid nature because, on the one hand, it is based on the synthesis of the equations defining the reference model and the adjustable model, and on the other hand it integrates control organs derived from artificial intelligence, such us the fuzzy logic.

\subsubsection{Structure of FM-MRAS observer}

The structure of the FM-MRAS observer is illustrated in Figure 3.

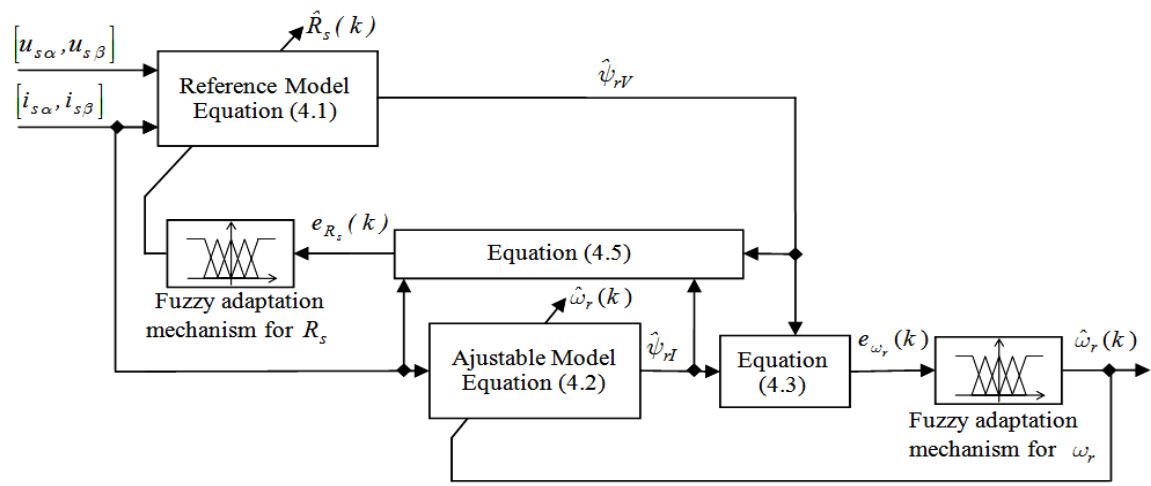

Figure 3. Structure of the observer underFM-MRASapproach 


\subsubsection{Synthesis of fuzzy adaptation mechanisms}

The observation of the behavior of the fuzzy mutual-MRAS shows that the significant quantities for the simultaneous estimation of the motor speed and the stator resistance are; the error $e(k)$ and its change rate $\Delta e(k)$ for the adaptation mechanism whose are the inputs of the fuzzy correctors.The two fuzzy controllers are chosen of identical structure, proportional-integral with incremental output, that is to say that their outputs represent the increments of the quantities to estimate $\omega_{r}(k)$ and $R_{s}(k)$. The structure of the PIFuzzy adaptation mechanisms is identical for speed and rotor resistance estimation shown in Figure 4.The gains $G_{e}, G_{\Delta e}$ and $G_{\Delta u}$ are introduced to normalize the inputs and the output of the estimator controller, they are chosen by simulation test to guarantee the belonging of the variables to the associated fuzzy set and thus to adjust the sensitivity of the regulator without changing the structure.

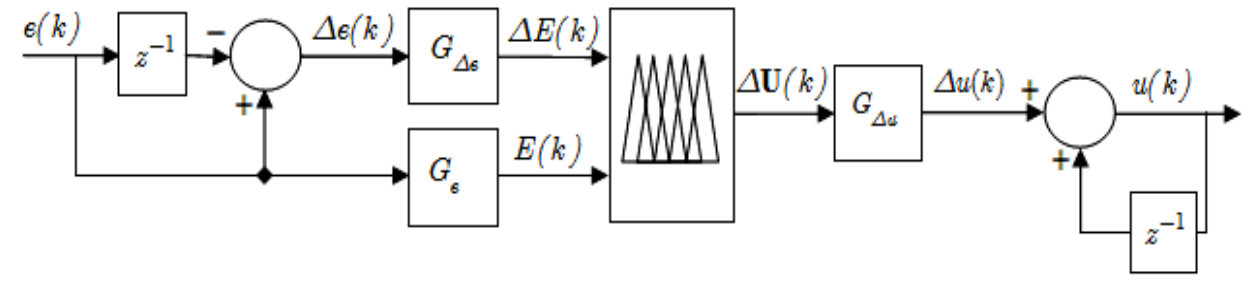

Figure 4. Structure of fuzzy adaptation mechanism

Normalized inputs are similary determined at time $k$ is being as.

$$
E(k)=G_{e} \cdot \mathrm{e}(k)
$$

and

$$
\Delta E(k)=G_{\Delta e}[e(k)-e(k-1)]
$$

and the estimated values of the rotor pulsation or the stator resistance are similary deduced by the relation

$$
u(k)=u(k-1)+G_{\Delta u} \cdot \Delta \boldsymbol{U}(k)
$$

or

$$
u(k)=u(k-1)+\Delta u(k)
$$

with $u(k)$ represents $\widehat{\omega}_{r}(k)$ or $\widehat{R}_{s}(k)$.

Fuzzy logic controllers are based on three well known blocs: fuzzyfication bloc, block ofrule basesanddefuzzyfication block [8], [22]. Figure 5, shows the partition of the speech universe and the membership functions retained for the fuzzy speed estimator (similar choices have been retained for the fuzzy stator resistance estimator).
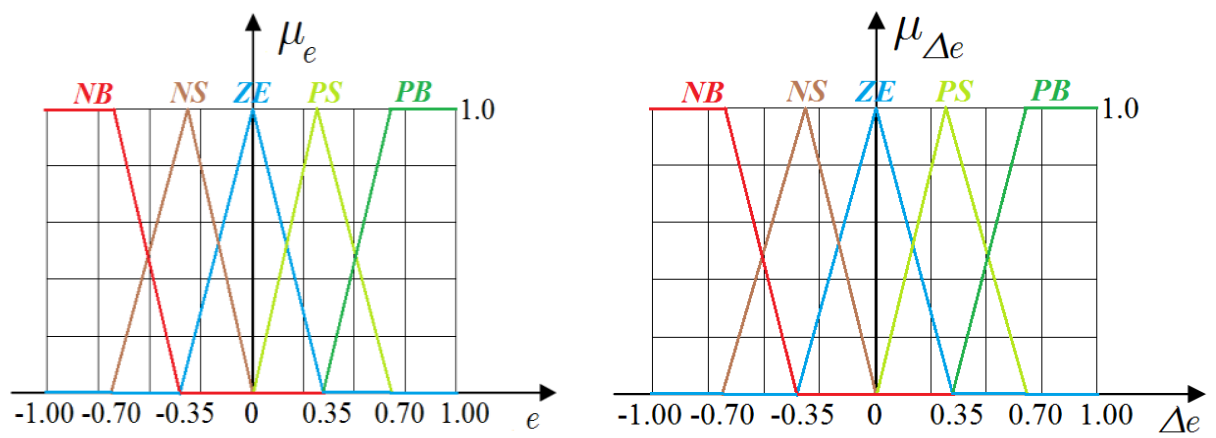

Figure 5. Fuzzification and partition of the speech universe for the fuzzy corrector speed estimator 


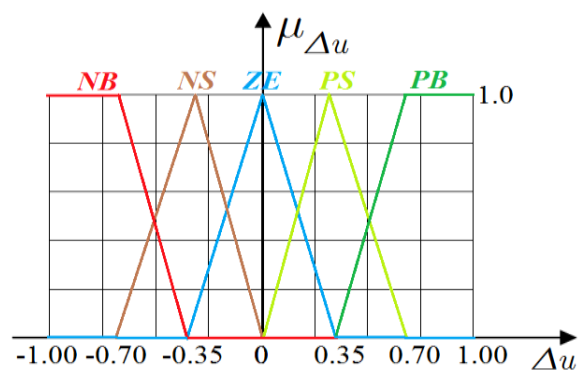

Figure 5. Fuzzification and partition of the speech universe for the fuzzy corrector speed estimator(continue)

For the membership functions, the triangular and trapezoidal shapes have been retained for the sake of simplicity. After several attempts, a partition of the speech universe with five fuzzy subsets (NB: negative big, PB: positive big, NS: negative small, PS: positive small, ZE: zero equal) was favored for the two controllers.For the treatment of the inferences, the method "Max-Min" of Mamdani was chosen for the two controllers, the method of defuzzification retained is that of the center of gravity. The selected rule base has twenty-five fuzzy rules and is described by the inference matrix shown in Table 1. According to the controller considered $e, \Delta \mathrm{e}$ and $\Delta u$ represent respectively $e_{w_{r}}(k), \Delta e_{w_{r}}(k), \Delta \widehat{\omega}_{r}(k) \quad$ or $e_{R_{S}}(k), \Delta e_{R_{S}}(k), \Delta \hat{R}_{S}(k)$.

Table 1. Inference matrix defined for both fuzzy controllers

\begin{tabular}{cccccc}
\hline $\begin{array}{r}\Delta e \\
e u\end{array}$ & NB & NS & ZE & PS & PB \\
\hline NB & NB & NB & NS & PB & PS \\
NS & ZE & NS & ZE & PS & ZE \\
ZE & PB & PB & ZE & PS & NB \\
PS & ZE & PS & PB & NS & NB \\
PB & PB & PS & NS & NS & NB \\
\hline
\end{tabular}

\section{RESULTS AND ANALYSIS}

In order to demonstrate and validate the high performance of the proposed sensorless slidingmodebased control system associated with FM-MRAS observer, some selected simulations are presented underthe software Matlab/Simulink environment. This approach is investigated by introducing a variation of load torque and the reference speed using a simultaneous stator resistance and rotor speed identificationof position sensorless induction motor to accurately estimate very low speeds. The stator resistanceis estimated concurrently with the speed estimation to compensate for the fluctuation in stator resistance. The study is applied for both induction motor operating modes; the motor mode and the regenerating mode. In this mode of operation, the IM issubjected to positive load torque when running at reverse speed. The parameters and constants of the machine are shown in Table 2.

The accuracy of speed estimation has been verified by giving a set of steps of speed refences, two benchmarks are proposed and discussed in this paper as two case studies.

- The first, designated "case 1", shows the operation of the machine in both directions at high speeds.

- The second, called "case 2", discusses different operating low speed levels even in very low speed.

Table 2. Induction motor parameters

\begin{tabular}{ll}
\hline Designation & Quantity \\
\hline Rated power & $1.5 \mathrm{~kW}$ \\
Rated voltage & $220 \mathrm{~V}$ \\
Rated speed & $1428 \mathrm{rpm}$ \\
Nominal frequency & $50 \mathrm{~Hz}$ \\
Stator resistance & $4.85 \Omega$ \\
Rotor resistance & $3.805 \Omega$ \\
Stator inductance & $0.274 \mathrm{H}$ \\
Rotor inductance & $0.274 \mathrm{H}$ \\
Mutual inductance & $0.258 \mathrm{H}$ \\
Number of pole pairs & 2 \\
Moment of inertia & $0.031 \mathrm{~kg} / \mathrm{m} 2$ \\
Friction coefficient & $0.00114 \mathrm{Nm} . \mathrm{s} / \mathrm{rd}$ \\
\hline
\end{tabular}

Sensorless nonlinear sliding mode control of the induction machine at very low speed ... (Mokhtar Touam) 


\subsection{Case 1: high speeds operation}

In this case, the speed curve begins with a zero speed until it varies from 0 to $20 \mathrm{rad} / \mathrm{s}$ for an interval of [0.75-8] s, it remains constant for an interval of [0.8-3] s. The speed then increases from 20 to $100 \mathrm{rad} / \mathrm{s}$ during $1 \mathrm{~s}$, it remains again constant at $100 \mathrm{rad} / \mathrm{s}$ during an interval of [4]-[6] s, after that, the speed decreases to reach -100 $\mathrm{rad} / \mathrm{s}$ during $1 \mathrm{~s}$ and remains constant until $9 \mathrm{~s}$, then increases to $20 \mathrm{rad} / \mathrm{s}$ for an interval of [9-9.8] $\mathrm{s}$ and remains constant until $12 \mathrm{~s}$, see Figure 6. The load torque as disturbance is varied two times from 0 to $7 \mathrm{Nm}$ when the speed is constant for both directeanreverse sense for the two intervals respectively [4.5-5.5] s, [7.5-8.5] s, see Figure 7.

The excellent precision of simultaneous estimation of rotor speed and stator resistance allowed to have very satisfactory performances in tracking even under torque steps perturbation. The zero-crossing area presents significant tracking and estimation errors. The stability is tested with respect to the reduction of the chattering phenomenon in regenerating mode of operation. In this region of operation, the motor is running in the negative speed region with positive load torque applied. Since the motor speed estimation depends on the online stator resistance estimation, so if any worsening in stator resistance estimation is fed back to the speed estimation causing instability.

It is to notice that the estimation of the stator resistance is valid under steady state operation, see Figure 8. As the rate of change in the stator resistance due to temperature is very low compared to the electrical time constants of induction motor, the FM-MRAS estimator can be disabled during transient conditions. We also notice that the resistance changes slightly when the load rises and the speed crosses the zero zone, and this is due to the increase in temperature at these moments.
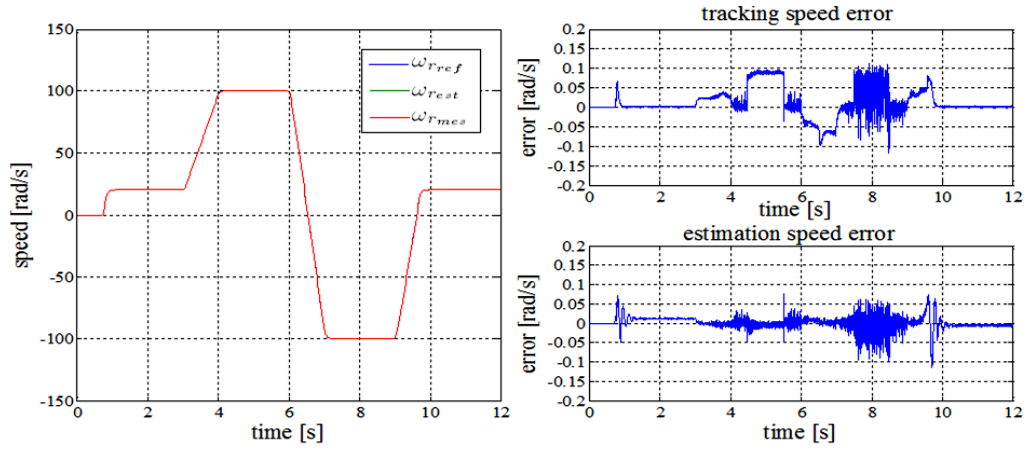

Figure 6. IM speed tracking and estimation in different operating modes
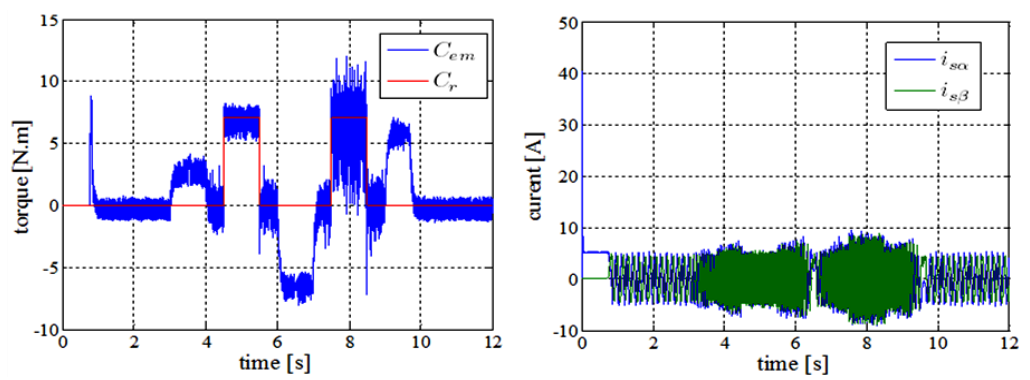

Figure 7. Electromagnetic and load torques and their influence on stator currents
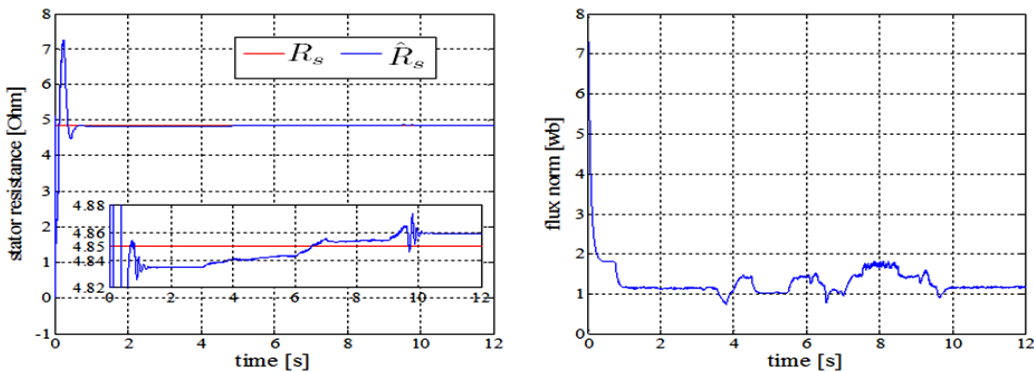

Figure 8. Stator resistance estimate with respect to the loadtorque and norm flux 


\subsection{Case 2: very low speeds operation}

In this case we applied a benchmark of very low speed levels with testing the induction machine reponse in both motor and regenerating modes. The IM speed is taken as zero for the interval of [0-1.5] s, it then increases to $10 \mathrm{rad} / \mathrm{s}$ during $0.1 \mathrm{~s}$ and then remains constant until it reaches $3.5 \mathrm{~s}$, the speed varies from $10 \mathrm{rad} / \mathrm{s}$ to $-10 \mathrm{rad} / \mathrm{s}$ for the interval of [3.5-3.6] $\mathrm{s}$ and remains constant until it reaches $4.9 \mathrm{~s}$, then it increases from $-10 \mathrm{rad} / \mathrm{s}$ to $-2 \mathrm{rad} / \mathrm{s}$ during $0.1 \mathrm{~s}$, after that it increases again until it reaches just $1 \mathrm{rad} / \mathrm{s}$ for the interval of [5.3-6.1] $\mathrm{s}$ and keeps this value during $1.7 \mathrm{~s}$ then it decreases again to reache $-5 \mathrm{rad} / \mathrm{s}$ at time $7.9 \mathrm{~s}$ and remains constant for the interval [7.9-9.3] s then it increases to reach the zero speed and remains constant for the interval of [9.4-9.9] $\mathrm{s}$ then it increases to $5 \mathrm{rad} / \mathrm{s}$ during $0.1 \mathrm{~s}$ to be constant until it attains $12 \mathrm{~s}$, see Figure 9. At the same time, the load torque is varied three times for various intervals: [2.2-3] s, [4.2-5.5] s and [8.39.2] s corresponding to variation from 0 to $3 \mathrm{Nm}$, see Figure 10.

It should be noted that through the given tracks, we notice that the induction machine operates as a generator during both periods [4.2-5.5]s and [8.3-9.2]s respectively such that the IM torque and the speed have not from the same signs. The simulation results show an insignificant tracking and estimation errors even in the zone of unobservability (instability) where the speed crosses the zero zone.In order to investigate the performance of the controlled system for parameter variations in stator resistance. The Figure 11, presents various changes in stator resistance.
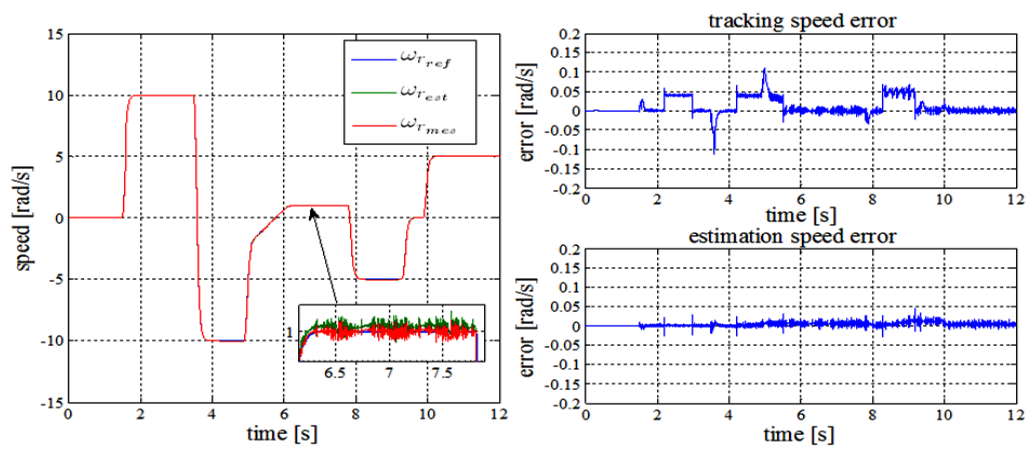

Figure 9. IM very low speed tracking and estimation in different operating modes
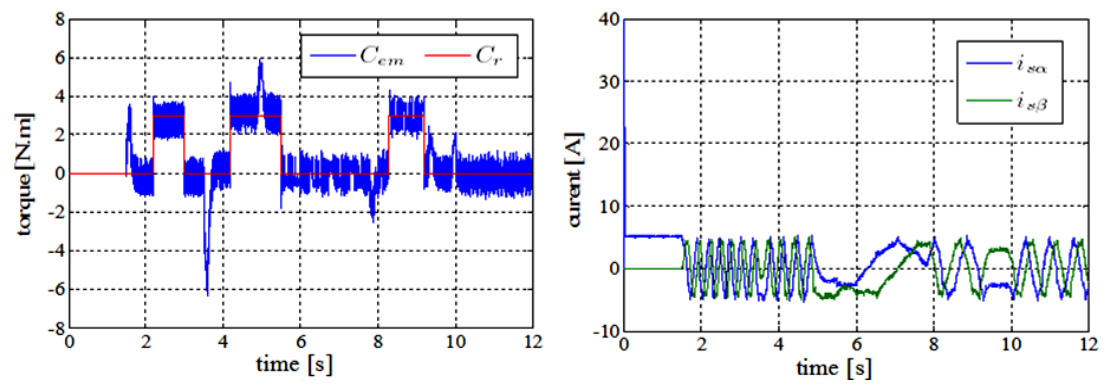

Figure 10. Performance for electromagnetic torque and stator currents
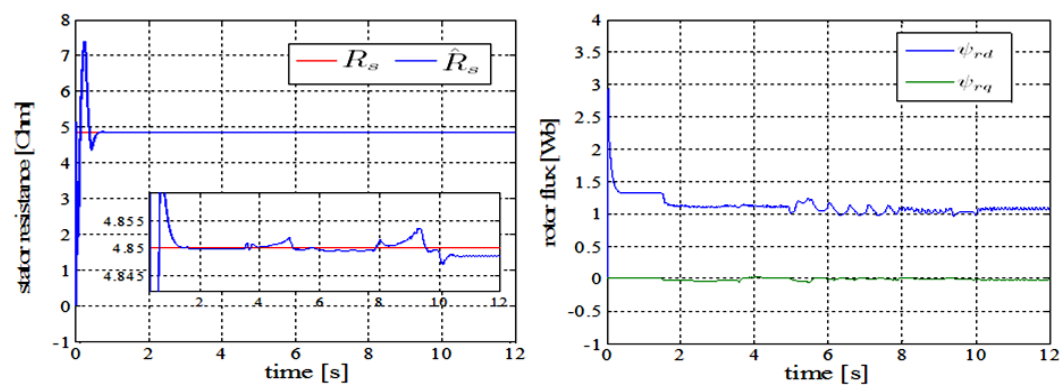

Figure 11. Stator resistance adaptation with respect to the load torque and flux 
At the induction machine start-up, we notice stator resistance estimation overshoots whose decrease when the stator resistance increases, see Figure 12. To test the robustness of tocontolled system we applied $80 \%$ increase than $40 \%$ decrease in stator resistance respectively, see tracking and estimation speed errors Figures 12 and 13 (a)-(d). The simultaneous parallel estimation of the stator resistance and rotor speed enables the control system to eject perturbations and parameter variations. The performance results obtained for the proposed control strategy are acceptable and useful compared to other existing works [9], [23]-[26].

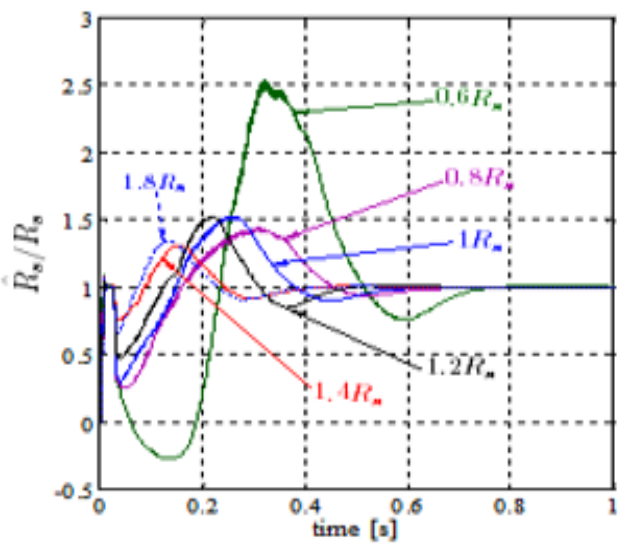

Figure 12. Robustness test of estimated stator resistance during transient conditions

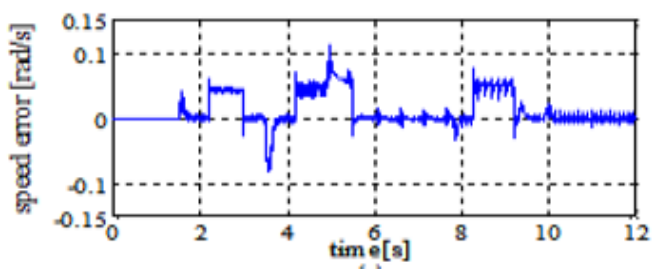

(a)

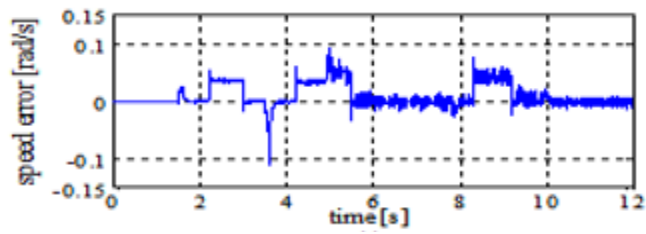

(c)

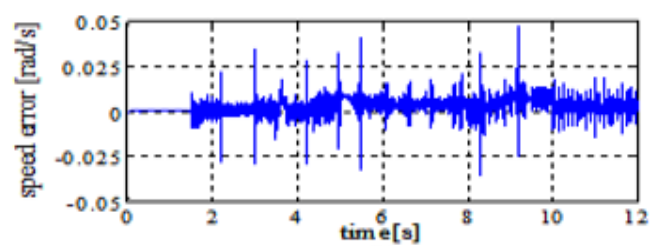

(b)

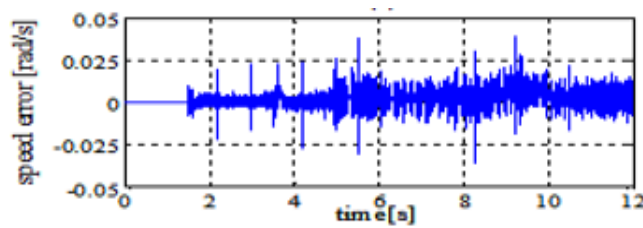

(d)

Figure 13. These figures are;(a) tracking speed errors for $+80 \%$ change in stator resistance, (b) estimation speed errors for $+80 \%$ change in stator resistance, (c) tracking speed errors for $-40 \%$ change in stator resistanceand, (d) estimation speed errors for $-40 \%$ change in stator resistance

\section{CONCLUSION}

In this paper, fuzzy mutual MRAS simultaneous speed a stator resistance estimation has been drived for speed sensorless nonlinear sliding mode control of induction machine. The introducing of fuzzy mutual MRAS estimation in this approach achieved a high perfomance and low parameter variations sensivity given the difficulty comprises estimation at very low speeds where the fundamental excitation is low and the observer performance tends to be poor.The proposed sensorless nonlinear sliding mode control scheme showed a good behavior in the transient and steady states, with an excellent disturbance rejection of load torque and robustness against parameter variations. The simulation results demonstrate the effectiveness of proposed control over different operating conditions, a very good speed tracking with precise estimation in very low and zero speeds. Some perspectives of this present work can be about minimisation or elimination of oscillations in regenerating mode when the speed crosses the zero zone and also about using Dspace 1104 card to implement this approach in real-time. 


\section{REFERENCES}

[1] V. Utkin, "Variable structure systems with sliding modes," in IEEE Transactions on Automatic Control, vol. 22, no. 2, pp. 212-222, April 1977, doi: 10.1109/TAC.1977.1101446.

[2] E. Slotine and W. Li, Applied Nonlinear Control, Englewood Cliffs, NJ: Prentice hall, vol. 199, no. 1, 1991.

[3] M.S. Zaky, M. Khater, H. Yasin, and S. S. Shokralla, "Very low speed and zero speed estimations of sensorless induction motor drives,"ELSEVIER, Electric Power Systems Research,vol. 80, no. 2, pp. 143-151, February 2010, doi: 10.1016/j.epsr.2009.07.012.

[4] M. Bednář, "New Approach to Induction Motor Drive Sensorless MRAS Control," Doctoral Thesis, Prague, 2014.

[5] V. Vasic', and S. Vukosavic', "Robust MRAS-Based Algorithm for Stator Resistance and Rotor Speed Identification," IEEE Power Engineering Review, vol. 21, no. 11, pp. 39-41, November 2001.

[6] V. Vasic, S. N. Vukosavic, and E. Levi, "A stator resistance estimation scheme for speed sensorless rotor flux oriented induction motor drives," in IEEE Transactions on Energy Conversion, vol. 18, no. 4, pp. 476-483, Dec. 2003, doi: 10.1109/TEC.2003.816595.

[7] S. Chekroun, M. Zerikat, A. Mechernene, and N. Benharir, "Novel Observer Scheme of Fuzzy-MRAS Sensorless Speed Control of Induction Motor Drive,” IOP Conf. Series: Journal of Physics: Conf. Series, vol. 783, no. 1, p. $012045,2017$.

[8] Y-C Luoand, and C-L Tsai, "Speed estimation vector-controlled induction motor drive based on fuzzy logic control flux estimator," Journal of Low Frequency Noise, Vibration and Active Control,vol. 38, no. 3-4, pp. 1220-1233, 2019, doi: 10.1177\%2F1461348418784187.

[9] M. Zairand, and A. Hazzab, "MRAS Speed Sensorless Vector Control of Induction Motor Drives Using Predictive Adaptation Mechanism," International Journal of Power Electronics and Drive System (IJPEDS),vol. 9, no. 4, pp. 1523-1533, December 2018, doi: 10.11591/ijpeds.v9.i4.pp1523-1533.

[10] Z. Kandoussi et al., "Sensorless Control of Induction Motor Drives Using an Improved MRAS Observer," J. Electr. Eng. Technol., vol. 12, no. 4, pp. 1456-1470, January 2017, doi: 10.5370/JEET.2017.12.4.1456.

[11] M. Krishna S. and F. Daya. J. L, "Effect of Parametric Variations and Voltage Unbalance on Adaptive Speed Estimation Schemes for Speed Sensorless Induction Motor Drives," International Journal of Power Electronics and Drive System (IJPEDS), vol. 6, no. 1, pp. 77-85, March 2015.

[12] A. Mechernene, M. Zerikat, and S. Chekroun, "Adaptive Speed Observer using Artificial Neural Network for Sensorless Vector Control of Induction Motor Drive,” Automatika, vol. 53, no. 3, pp. 53-3.68, 2012, doi: 10.7305/automatika.53-3.68.

[13] M. Ghanes, "Observation Et Commande De La Machine Asynchrone Sans Capteur Mécanique," 2009 Doctoral Thesis, Central School of Nantes, Institut de Recherche en Communications et Cybernétique de Nantes, 2005.

[14] W. Perruquetti and J. P. Barbot, "Sliding Mode Control In Engineering," CRC press,2002.

[15] M. Abid, A. G. Aissaoui, Y. Ramdani, and A. K. Zeblah, "Sliding Mode Speed and Flux Control of Field-Oriented Induction Machine," Acta Electrotechnica et Informatica, vol. 1, no. 7,pp, 1-7, 2007.

[16] A. W. Aditya, D. C. Happyanto, and B. Sumantri, "Application of Sliding Mode Control in Indirect Field Oriented Control (IFOC) for Model Based Controller," EMITTER International Journal of Engineering Technology,vol. 5,no. 2, pp. 255-269, December 2017, doi: 10.24003/emitter.v5i2.193.

[17] C. M. R. Oliveira, M. L. Aguiar, J. B. A. Monteiro, W. C. Pereira, G. T. Paula, and M. P. Santana, "Vector control of induction motor using a sliding mode controller with chattering reduction," 2015 IEEE 13th Brazilian Power Electronics Conference and 1st Southern Power Electronics Conference, 2015, pp. 1-6, doi: 10.1109/COBEP.2015.7420071.

[18] M. Singh, K. B. Mohanty, and B. Subudhi, "Sliding mode control of a feedback linearized induction motor using TS fuzzy based adaptive Iterative Learning Controller," 2011 IEEE Ninth International Conference on Power Electronics and Drive Systems, 2011, pp. 625-630, doi: 10.1109/PEDS.2011.6147316.

[19] P. Vas, Sensorless Vector and Direct Torque Control, Oxford Science Publications, Oxford New York Tokyo, Oxford University Press, 1998.

[20] T. J. Fu, and W. F. Xie, "A novel sliding-mode control of induction motor using space vector modulation technique," ISA Transactions, vol. 44, no. 4, pp. 481-490, March 2005, doi: 10.1016/S0019-0578(07)60055-X.

[21] S. M. Krishna, and J. L. F. Daya, "MRAS speed estimator with fuzzy and PIstator resistance adaptation for sensorlessinduction motor drives using RT-lab," ScienceDirect,Engineering and Material Sciences, vol. 8, pp. 121126, September2016, doi: 10.1016/j.pisc.2016.04.013.

[22] D. J. Cherifi, Y. Miloud, and A. Tahri, "Performance Evaluation of a Sensorless Induction Motor Drive Using a MRAS Speed Observer," Journal Of Current Research in Science 2013, vol 1, no. 2, pp. 71-78, 2013.

[23] C. Djamila, M. Yahia, and T. Ali, "Simultaneous Estimation of Rotor Speed and Stator Resistance in Sensorless Indirect Vector Control of Induction Motor Drives Using a Luenberger Observer," IJCSI International Journal of Computer Science Issues, vol. 9, no. 3, no. 2, pp. 325-335, May 2012.

[24] Y.-K. Lu, "Adaptive Fuzzy Integral Sliding-Mode Regulator for Induction Motor Using Nonlinear Sliding Surface," International Journal of Power Electronics and Drive System (IJPEDS), vol. 5, no. 4, pp. 512-519, April 2015.

[25] Y.A. Zorgani, M. Jouili, Y. Koubaa, and M. Boussak, "A Very-Low-Speed Sensorless Control Induction Motor Drive with Online Rotor Resistance Tuning by Using MRAS Scheme," International Power Electronics and Drives,vol. 4, no. 1, pp. 171-186, 2018, doi: 10.2478/pead-2018-0021.

[26] T. Belberki, B. Bouchiba, I. K. Bousserhane, and H. Becheri, "A study of sensorless vector control of IM using neural network luenberger obeserver," International Journal of Power Electronics and Drive System (IJPEDS), vol. 11, no. 3, pp. 1259-1267, September 2020, doi: 10.11591/ijpeds.v11.i3.pp1259-1267. 


\section{BIOGRAPHIES OF AUTHORS}

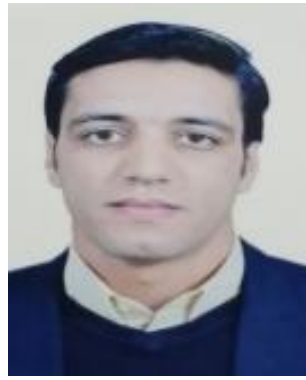

Mokhtar Touam was born in Saida in Algeria in 1987. He received his BS degree in electrical engineering from IMSI Oran university (Algeria) in 2009, the MS degree in electrical engineering from ENP Oran university (Algeria) in 2012. His research interest are non linear control and observers applied in induction motor. He's currently preparing his Ph.D. degree.

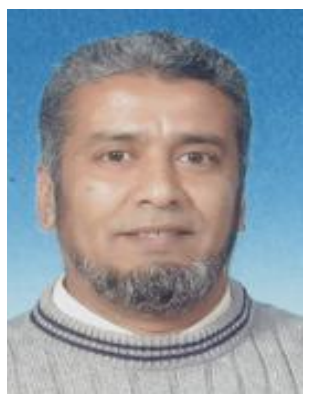

Mohammed ChenafaHe received his BS degree in electronic engineering from USTO (Algeria) in 1979, the MS degree in signal processing and roboticfrom USTO (Algeria) in 1998, and the Ph.D degree in engineering control from USTO (Algeria) in 2005. He is currently professor of automatic control at ENP-Oran (Algeria). His research interests are non linear control, advanced control and observers applied in induction motor and manipulator robot.

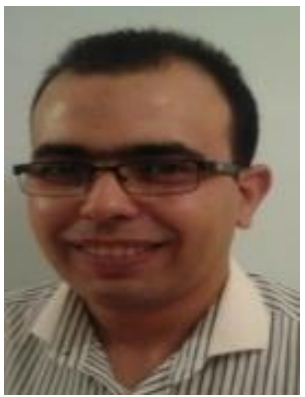

Soufyanechekroun was born in Tlemcen, Algeria in 1983. He received his B.S from University of Sciences and Technology of Oran-Algeria in 2006 and M.S degrees from National School of Oran, ENP-Oran in 2009 and Ph.D degrees in Automatic from University of Sciences and Technology of Oran-Algeria in 2016. Following graduation, he joined the department of Electrical Engineering of ENP-Oran as a research associate. Actually, he is associate Professor at University Mustapha Stambouli of Mascara- Algeria. His research interests include electrical machines and development of intelligent applications and the practical developments of high-performance electrical motor derives and their related knowledge control schemes.

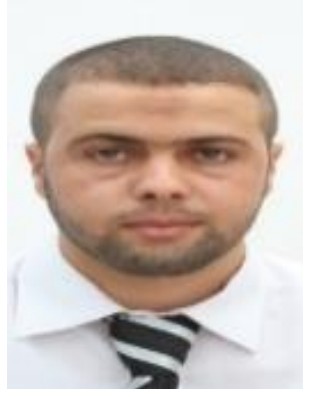

Ramzi Salimwas was born in Setif, Algeria in 1985. He received hisengineer degree in Instrumentation from the Institute of Maintenance and Industrial Security (Oran) in 2009, the MS degree in Automatic control in 2012 from E.N.P of Oran; he received her Ph.D degree in Electrical engineering in 2019 from E.N.P of Oran. His research interests are Advanced non linear control and observers applied in electro-mechanical and space craft systems. 